OPEN

SUBJECT AREAS:

ENVIRONMENTAL

SCIENCES

APPLIED MICROBIOLOGY

Received

4 September 2014

Accepted

15 December 2014

Published

14 January 2015

Correspondence and requests for materials should be addressed to R.L. (lirong@njau.edu.

$\mathrm{cn})$

\section{Utilization of different waste proteins to create a novel PGPR-containing bio-organic fertilizer}

\author{
Yan Huang ', Li Sun ${ }^{2}$, Jianshu Zhao ${ }^{3}$, Rong Huang ${ }^{3}$, Rong Li ${ }^{1,3}$ \& Qirong Shen ${ }^{1,2}$
}

'Jiangsu Key Lab and Engineering Center for Solid Organic Waste Utilization, Nanjing Agricultural University, Nanjing, 210095 , China, ${ }^{2}$ National Enginnering Research Center for Organic-based Fertilizers, Nanjing Agricultural University, Nanjing, 210095 , China, ${ }^{3}$ Jiangsu Collaborative Innovation Center for Solid Organic Waste Resource Utilization, Nanjing Agricultural University, Nanjing, 210095, China.

High-quality bio-organic fertilizers (BIOs) cannot be produced without the addition of some proteins, while many waste proteins are haphazardly disposed, causing serious environmental pollution. In this study, several waste proteins were used as additives to assist with the reproduction of the functional microbe (Bacillus amyloliquefaciens SQR9) inoculated into matured composts to produce BIOs. An optimized composition of solid-state fermentation (SSF) raw materials was predicted by response surface methodology and experimental validation. The results showed that $7.61 \%(\mathrm{w} / \mathrm{w}, \mathrm{DW}$, the same below) rapeseed meal, 8.85\% expanded feather meal, $6.47 \%$ dewatered blue algal sludge and $77.07 \%$ chicken compost resulted in maximum biomass of strain SQR-9 and the maximum amount of lipopeptides 7 days after SSF.

Spectroscopy experiments showed that the inner material structural changes in the novel SSF differed from the control and the novel BIO had higher dissolved organic matter. This study offers a high value-added utilization of waste proteins for producing economical but high-quality BIO.

ong-term over application of chemical fertilizers used to ensure high crop yields has caused environmental problems, damaged soil structures and deteriorated soil microbial communities. Therefore, much more environmentally friendly, sustainable and organic agricultural practices have been developed to complement chemical-based agriculture ${ }^{8}$. Among them, the application of bio-organic fertilizers (BIOs) that contain beneficial microbes and can not only supply plant nutrients but also improve soil fertility ${ }^{17}$ has been proven to be an effective practice. Plant growth-promoting rhizobacteria (PGPR) have been applied in agriculture for more than 60 years. In How Microbes can help feed the world", the authors state that "Producing more food with fewer resources may seem too good to be true, but the world's farmers have trillions of potential partners that can help achieve that ambitious goal. Those partners are microbes"2. Many researchers have already demonstrated that combining PGPR with certain organic substrates to create bio-organic fertilizers could enhance the activity of PGPRs ${ }^{3,4,27}$. Currently, the application of these BIOs is becoming more popular in China, as more and more farmers are recognizing the fact that BIOs can both promote plant growth and protect plant roots from soil-borne pathogens ${ }^{27}$.

In our previous studies, the addition rate of rapeseed cakes as the source of proteins could only be higher than $30 \%$ of the total organic substrates, and the BIOs created a significant effect on the promotion of plant growth and on the control of soil-borne diseases after they were applied to soils ${ }^{3,4}$. However, a simple comparison of matured compost $\left(80\right.$ US $\$$ ton $^{-1}$ ) to oil rapeseed cakes $\left(500\right.$ US $\$$ ton $^{-1}$ ) indicated that the production costs of adding the rapeseed cakes into matured composts were significantly greater, which would limit the large-scale extension of $\mathrm{BIOs}^{27}$. Thus, there is an urgent need to discover materials to replace oil rapeseed cakes as additive nutrients to produce low-cost but high-quality BIOs.

The blooming of cyanobacteria is a ubiquitous phenomenon in eutrophic lakes, reservoirs, and polluted waters around the world ${ }^{11}$. Refloatation of blue algae after blooming has been considered to be the most efficient approach for retrieving nitrogen and phosphorus from lakes. As much as $61.76 \%$ of the total solids in blue algae is protein ${ }^{11}$. Poultry feathers, another agricultural waste, are produced in large amounts due to the rapid development of the poultry industry in China and in the world, and appropriate resource utilization is required to avoid environmental pollution. Expanded feather powder puffed from poultry feathers contains $86.8 \%$ crude protein $^{9}$ and has been reported to create fertilizer to promote banana growth. Therefore, if these waste protein sources can be used as protein candidates for the SSF of PGPR, the production costs of BIOs can be significantly decreased. 


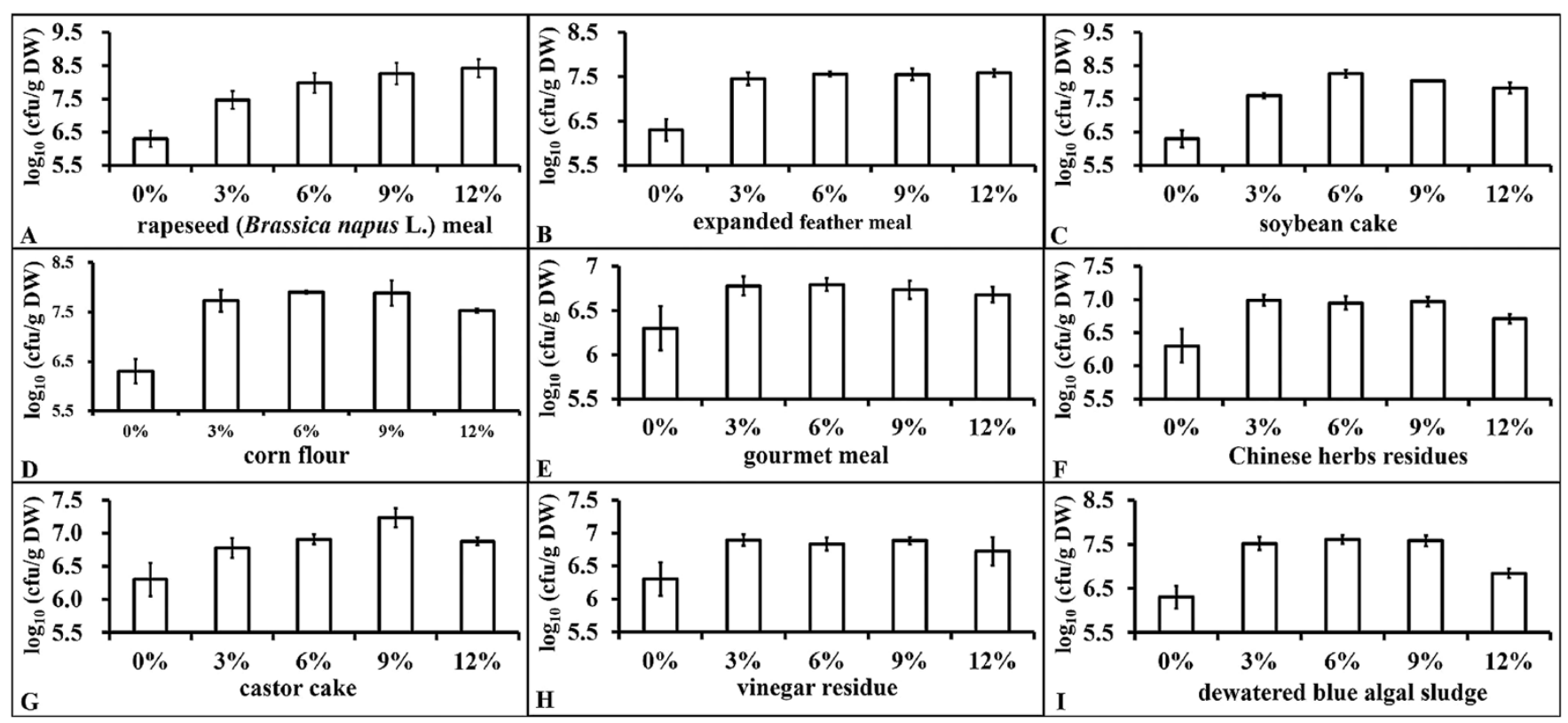

Figure 1 Selection of composting ingredients of rapeseed (Brassica napus L.) meal (A), expanded feather meal (B), soybean cake (C), corn flour (D), gourmet meal (E), Chinese herbs residues (F), castor cake (G), vinegar residue (H) and dewatered blue algal sludge (I).

During SSF, previous studies have mainly focused on the cell density and yields of functional substances such as lipopeptides $^{4,5,25,28}$, but the transformation process of raw materials is poorly understood. In terms of the SSF process, fluorescence excitationemission matrix (EEM) spectroscopy has already been used to determine protein-like, fulvic acid-like and humic acid-like substances, and a Fourier-transform infrared (FTIR) method was successfully used to study the transformation of organic matter owing to its specificity, which is similar to fingerprints ${ }^{1,6,26}$. However, no report has documented the characterization of the material transformation process during BIO production using these methods.

The strain Bacillus amyloliquefaciens SQR9 was previously reported as a good PGPR. Cao et al. $(2011)^{3}$ showed that combining strain SQR-9 with rapeseed cake and matured composts to create a BIO showed a significantly antagonistic effect, and the numbers of the functional bacterium in the fertilizer could be as high as $10^{9} \mathrm{CFU}$ $\mathrm{g}^{-1}$ dry weight (DW). SQR9-containing bio-organic fertilizers were also successfully created by using algal sludge and matured composts, but the cell density of SQR- 9 was only $5 \times 10^{7} \mathrm{CFU} \mathrm{g}^{-127}$. Thus, it is necessary to explore an optimum SSF process that can not only reduce the cost of bio-organic fertilizers by replacing the rapeseed cake with other waste proteins but also ensure a higher level of cell density.

To achieve maximum production in SSF, several methods have been applied, such as orthogonal experiments, artificial networks (ANN) and response surface methodology (RSM). Among them, RSM has been proven to be an economical method for optimizing variables to ensure maximum production by identifying the effective factors, interactions and optimum conditions via limited experiments ${ }^{24,28}$. The objectives of this study were to choose better ratios of different waste proteins and matured composts as SSF media, to explore the efficient SSF technology using RSM, and to monitor the transformation of water extracted organic matter and the changes in structures of biopolymers during the SSF process using EEM and FTIR for elucidating the interactions of the raw material transformation and the growth of PGPR cells.

\section{Results}

Composing parameters and single factors selection. During the SSF procedure, the cell density increased over the initial three days and then decreased until the end of SSF (Fig. S1A); thus, cell density on the third and last days was monitored in the subsequent experiments. A similar result was also reported by Zhang et al. $(2014)^{27}$, in which the cell density decreased after four days. No significant correlations were observed between the cell density and the ambient temperature $\left(20-45^{\circ} \mathrm{C}\right)$ (Fig. S1B). Initial moisture content had a normal distribution trend effect on cell density (Fig. S1C), and no significant difference was observed among treatments with a moisture content of approximately $50 \%$ (Fig. S1D), indicating the initial moisture around $50 \%$ is better for SSF to produce more cell densities. The cell density increased along with an increase in the inoculation amount when the added inoculation amount was less than $7.5 \%$, which is a suitable inoculation amount (Fig. S1E). In addition, on the third day and the last day, no significant difference in cell density was observed when the frequency of heap turning was more than twice per day (Fig. S1F). The frequency of heap turning has an effect on the dissolved oxygen in materials and on the heat of fermentation ${ }^{14}$; thus, heap turning twice per day was selected for further study.

The effects of different exogenous ingredients added to the cell density of SQR-9 are shown in Fig. 1. Compared to the control, adding any of the supplemental nutrient materials increased the cell density. The greatest cell density was obtained when $12 \%$ rapeseed cake was added, followed by $9 \%$ and $6 \%$ rapeseed cake. Moreover, the addition of soybean cake, feather powder, corn flour and dewatered blue algal sludge also enhanced the cell density to a certain extent, and these materials should be considered for further study.

Optimized SQR-9 biomass and amount of lipopeptides. The effects of all selected variables on the cell density of strain SQR-9 were determined according to PBD experiments, with the value varying from $0.11 \pm 0.01 \times 10^{8} \mathrm{CFU} / \mathrm{g} \mathrm{DW}$ to $2.86 \pm 0.03 \times$ $10^{8} \mathrm{CFU} / \mathrm{g}$ DW through 12 runs (Table 1 ); the results revealed that the optimization process was important and significant for cell density increases via SSF. Statistical analysis of the PBD experiment based on a base $10 \log$ transformation of cell density (Table 2) showed that three variables, $\mathrm{BX}_{2}$ (rapeseed meal; $\mathrm{P}=$ 0.013), $\mathrm{BX}_{4}$ (expanded feather meal; $\mathrm{P}=0.006$ ) and $\mathrm{BX}_{5}$ (dewatered blue algal sludge; $\mathrm{P}=0.042$ ) had significant effects on cell density. The P and F values of the Fisher's test were 0.019 and 
Table 1 | Plackket-Burnman experimental design and its response of strain SQR-9 biomass

Coded levels (Real values)

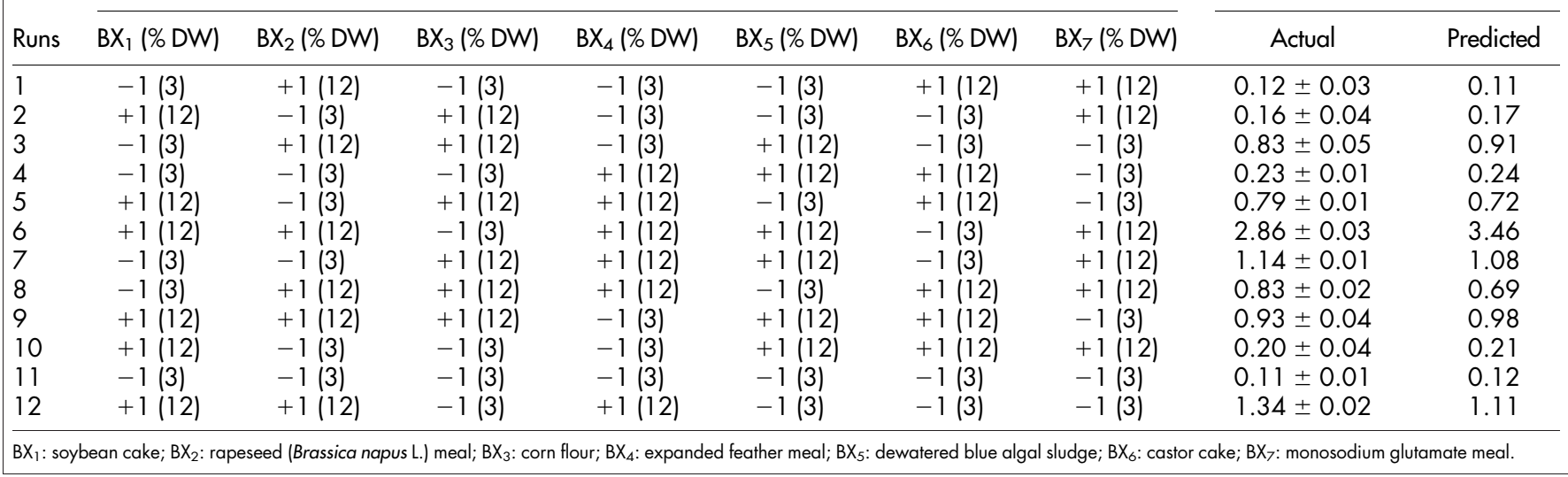

10.68, respectively, revealing that the model was statistically significant; the coefficient of determination $\left(\mathrm{R}^{2}\right)$ and Adj $\mathrm{R}^{2}$ were $94.92 \%$ and $86.04 \%$, respectively, indicating that the polynomial model has a high significance.

All of the results indicated that within an appropriate moisture content range, varying the amounts of rapeseed meal, feather powder, and dewatered blue algal sludge gradually could lead to higher cell density, with a maximum value of $3.24 \pm 0.36 \times 10^{8} \mathrm{CFU} / \mathrm{g}$ DW at ratios of $8 \%, 8 \%$ and $6 \%$, respectively, when the materials increased from $0 \%$ to $12 \%$ with a step change value of $2 \%$, revealing an adjacent region of a maximum value of cell density.

A further interaction effect of these three variables (renamed as $\mathrm{X}_{1}$ (rapeseed meal), $\mathrm{X}_{2}$ (expanded feather meal) and $\mathrm{X}_{3}$ (dewatered blue algal sludge)) on cell density and lipopeptides content was investigated using a central composite design (CCD) experiment. Twenty experiments were established with three independent variables at five levels $(-1.68,-1,0,+1,+1.68)$ including six center points (Table 3 ). After multiple regression analysis of the CCD experimental data, the following quadratic equation was used to infer the cell density (transformation at base $10 \log$ ):

$$
\begin{aligned}
Y_{(S Q R-9 \text { biomass })}= & 8.68+0.031 \mathrm{X}_{1}+0.20 \mathrm{X}_{2}+0.021 \mathrm{X}_{3} \\
& -0.061 \mathrm{X}_{1} \mathrm{X}_{2}+0.00225 \mathrm{X}_{1} \mathrm{X}_{3}-0.02 \mathrm{X}_{2} \mathrm{X}_{3} \\
& -0.12 \mathrm{X}_{1}^{2}-0.23 \mathrm{X}_{2}^{2}-0.094 \mathrm{X}_{3}^{2}
\end{aligned}
$$

where $\mathrm{Y}$ is the cell density of SQR-9 (predicted response), $\mathrm{X}_{1}$ is the amounts of rapeseed meal, $X_{2}$ is the amounts of feather powder and $\mathrm{X}_{3}$ is the amounts of dewatered blue algal sludge. In response to the amount of lipopeptides, Eq. 2 is expressed as:
$Y_{(\text {lipopeptides yield })}=16.26-0.15 \mathrm{X}_{1}-0.033 \mathrm{X}_{2}+0.18 \mathrm{X}_{3}$

$$
\begin{aligned}
& -0.19 \mathrm{X}_{1} \mathrm{X}_{2}-0.19 \mathrm{X}_{1} \mathrm{X}_{3}+0.052 \mathrm{X}_{2} \mathrm{X}_{3} \\
& -0.65 \mathrm{X}_{1}^{2}-0.49 \mathrm{X}_{2}^{2}-0.59 \mathrm{X}_{3}^{2}
\end{aligned}
$$

where $\mathrm{Y}$ is the amount of lipopeptides (predicted response).

Based on ANOVA analysis of biomass data from CCD, the model's linear term coefficients of $\mathrm{X}_{1}$ and $\mathrm{X}_{3}$, and the cross-product coefficients of $\mathrm{X}_{1} \mathrm{X}_{2}, \mathrm{X}_{1} \mathrm{X}_{3}$ and $\mathrm{X}_{2} \mathrm{X}_{3}$ were not significant $(\mathrm{P}>$ 0.05 ) in response to cell density. The linear term coefficient of $X_{2}$, as well as the quadric term coefficients of $\mathrm{X}_{1}{ }^{2}, \mathrm{X}_{2}{ }^{2}, \mathrm{X}_{3}{ }^{2}$, had highly significant $(\mathrm{P}<0.05)$ effects on cell density (transformation at base $10 \log )($ Table 4$)$, so Eq.1 can be simplified as:

$$
\begin{aligned}
Y_{(S Q R-9 \text { biomass })}= & 8.68+0.20 \mathrm{X}_{2}-0.12 \mathrm{X}_{1}^{2} \\
& -0.23 \mathrm{X}_{2}^{2}-0.094 \mathrm{X}_{3}^{2}
\end{aligned}
$$

After analysis of the lipopeptides yield data, the model linear term coefficients of $\mathrm{X}_{1}, \mathrm{X}_{2}$ and $\mathrm{X}_{3}$, and the cross-product coefficients of $\mathrm{X}_{1} \mathrm{X}_{2}, \mathrm{X}_{1} \mathrm{X}_{3}$ and $\mathrm{X}_{2} \mathrm{X}_{3}$ were not significant $(\mathrm{P}>0.01, \mathrm{P}>0.05)$, while the quadric term coefficients of $\mathrm{X}_{1}{ }^{2}, \mathrm{X}_{2}{ }^{2}, \mathrm{X}_{3}{ }^{2}$ had a highly significant $(\mathrm{P}<0.05, \mathrm{P}<0.01)$ effect on lipopeptides contents (Table 5$)$, so the

\begin{tabular}{|c|c|c|c|c|c|}
\hline Constant & & 7.6922 & 0.05091 & 151.10 & 0.000 \\
\hline $\mathrm{BX}_{2}$ & 0.4325 & 0.2163 & 0.05091 & 4.25 & $0.013^{*}$ \\
\hline $\mathrm{BX}_{3}$ & 0.2678 & 0.1339 & 0.05091 & 2.63 & 0.058 \\
\hline $\mathrm{BX}_{4}$ & 0.5538 & 0.2769 & 0.05091 & 5.44 & $0.006 *$ \\
\hline $\mathrm{BX}_{7}$ & -0.0542 & -0.0271 & 0.05091 & -0.53 & 0.623 \\
\hline $\mathrm{R}^{2}$ & $94.92 \%$ & & & & \\
\hline Adj R² & $86.04 \%$ & & & & \\
\hline
\end{tabular}
quadratic equation of Eq. 2 can be simplified as:

$$
Y_{(\text {lipopeptides yield })}=16.26-0.65 \mathrm{X}_{1}^{2}-0.49 \mathrm{X}_{2}^{2}-0.59 \mathrm{X}_{3}^{2}
$$

From the analysis of ANOVA of these two models, F values were 14.13 and 12.87, and $P$ values were 0.0001 and 0.0002 , indicating that Eq. 3 and Eq. 4 had a high reflection of this model.

$\mathrm{BX}_{1}$ : soybean cake; $\mathrm{BX}_{2}$ : rapeseed (Brassica napus $\mathrm{L}$.) meal; $\mathrm{BX}_{3}$ : corn flour; $\mathrm{BX}_{4}$ : expanded feather meal; $\mathrm{BX}_{5}$ : dewatered blue algal sludge; $\mathrm{BX}_{6}$ : castor cake; $\mathrm{BX}_{7}$ : monosodium glutamate meal. *indicate a significant difference at the 0.05 probability level according to Duncan test. 


\begin{tabular}{|c|c|c|c|c|c|c|c|}
\hline \multirow[b]{2}{*}{ Runs } & \multicolumn{3}{|c|}{ Coded levels (Real values) } & \multicolumn{2}{|c|}{ SQR-9 biomass $\left(\times 10^{8} / g\right.$ DW) } & \multicolumn{2}{|c|}{ Lipopeptides (mg/g DW) } \\
\hline & $X_{1}(\%$ DW) & $X_{2}(\% \mathrm{DW})$ & $\mathrm{X}_{3}(\% \mathrm{DW})$ & Actual & Predicted & Actual & Predicted \\
\hline 1 & $0(8)$ & $0(8)$ & $-1.68(0.95)$ & $2.29 \pm 0.27$ & 2.42 & $14.29 \pm 0.90$ & 14.30 \\
\hline 2 & $0(8)$ & $0(8)$ & $0(6)$ & $3.62 \pm 0.14$ & 5.01 & $15.73 \pm 1.30$ & 16.26 \\
\hline 3 & $+1(12)$ & $+1(12)$ & $+1(9)$ & $2.24 \pm 0.28$ & 2.45 & $13.96 \pm 1.31$ & 14.22 \\
\hline 6 & $-1(4)$ & $-1(4)$ & $-1(3)$ & $0.90 \pm 0.15$ & 0.74 & $14.43 \pm 1.59$ & 14.21 \\
\hline 7 & $+1(12)$ & $-1(4)$ & $-1(3)$ & $1.22 \pm 0.15$ & 1.39 & $14.49 \pm 1.51$ & 14.67 \\
\hline 8 & $0(8)$ & $0(8)$ & $+1.68(11.05)$ & $2.95 \pm 0.28$ & 2.75 & $14.99 \pm 0.86$ & 14.92 \\
\hline 9 & $0(8)$ & $0(8)$ & $0(6)$ & $7.16 \pm 0.21$ & 5.01 & $16.73 \pm 1.64$ & 16.26 \\
\hline 10 & $0(8)$ & $0(8)$ & $0(6)$ & $3.02 \pm 0.16$ & 5.01 & $16.58 \pm 1.22$ & 16.26 \\
\hline 11 & $0(8)$ & $0(8)$ & $0(6)$ & $6.84 \pm 0.19$ & 5.01 & $16.40 \pm 1.97$ & 16.26 \\
\hline 12 & $-1(4)$ & $-1(4)$ & $+1(9)$ & $0.98 \pm 0.01$ & 1.07 & $14.90 \pm 1.86$ & 14.85 \\
\hline 17 & $-1(4)$ & $+1(12)$ & $-1(3)$ & $2.82 \pm 0.14$ & 2.66 & $14.45 \pm 1.70$ & 14.42 \\
\hline 18 & $-1.68(1.27)$ & $0(8)$ & $0(6)$ & $1.85 \pm 0.21$ & 2.08 & $14.40 \pm 1.53$ & 14.68 \\
\hline 19 & $0(8)$ & $0(8)$ & $0(6)$ & $4.38 \pm 0.17$ & 5.01 & $16.26 \pm 1.33$ & 16.26 \\
\hline 20 & $+1(12)$ & $+1(12)$ & $-1(3)$ & $2.42 \pm 0.31$ & 2.38 & $14.04 \pm 1.45$ & 14.13 \\
\hline
\end{tabular}

$\mathrm{R}^{2}$ can be applied as a standard for examining the model, and doing so indicated that this model could explain $92.71 \%$ and $92.05 \%$ of the response of the variability in cell density and in lipopeptides production, respectively. Table 4 and Table 5 show that the predicted $\mathrm{R}^{2}$ of 0.8533 for the cell density experiment was in reasonable agreement with the Adj $\mathrm{R}^{2}$ of 0.8615 , while these two values were 0.7196 and 0.8490 in the lipopeptides production experiment, respectively. These results showed that the models and the quadratic equations were suitable and reasonable for the CCD experiment. The values of C.V. (1.32\% and $2.26 \%$, respectively) were quite low, indicating that these experiments had a satisfactory reliability and precision. Additionally, the lack of fit values $(\mathrm{P}=0.9878$ and 0.7707$)$ were not significant, which also indicated that the models were suitable for predicting cell density and lipopeptides content within the range of variables ${ }^{18}$.
Design-Expert version 8.0.6 (Stat-Ease, Inc., Minneapolis, MN, USA) can be used to create a three-dimensional response plot, which can be useful for understanding the relationship between variables and their responses ${ }^{24} .3 \mathrm{D}$ contour plots were produced by combining two of the three variables while keeping the other variable at zero, as shown in Fig. 2. These plots provide information on the optimum condition's location, and if the projection plane from surface plot is an ellipse, it reveals the significant interactions between variables ${ }^{28}$. As shown in Fig. 2A-Fig. 2F, the effects of the interaction between variables on cell density and the amount of lipopeptides were significant, and the optimum results were located inside the boundary. The plots in Fig. 2A-Fig. 2F allow a better understanding of the interactions between variables and the statistical model for optimizing the variables, which is helpful due to its aptness and applicability ${ }^{19}$.

\begin{tabular}{|c|c|c|c|c|c|}
\hline Model & & 9 & 1.56 & 14.13 & $0.0001 * *$ \\
\hline$X_{1}$ & 0.031 & 1 & 0.013 & 1.07 & 0.3263 \\
\hline$x_{2}$ & 0.20 & 1 & 0.52 & 42.77 & $<0.0001 * *$ \\
\hline$x_{3}$ & 0.008847 & 1 & 0.006116 & 0.5 & 0.4956 \\
\hline$x_{2} x_{3}$ & -0.020 & 1 & 0.003120 & 0.26 & 0.6244 \\
\hline$X_{1}^{2}$ & -0.12 & 1 & 0.20 & 16.22 & $0.0024 * *$ \\
\hline$X_{2}^{2}$ & -0.24 & 1 & 0.80 & 65.02 & $<0.0001 * *$ \\
\hline$x_{3}^{2}$ & -0.080 & 1 & 0.13 & 10.33 & $0.0093 * *$ \\
\hline Residual & & 10 & 0.12 & & \\
\hline Lack of fit & & 5 & 0.011 & 0.10 & 0.9878 \\
\hline
\end{tabular}

$\mathrm{X}_{1}$ : rapeseed (Brassica napus L.) meal; $\mathrm{X}_{2}$ : expanded feather meal; $\mathrm{X}_{3}$ : dewatered blue algal sludge.

**indicate a significant difference at the 0.01 probability level according to Duncan test. * indicate a significant difference at the 0.05 probability level according to Duncan test. 
Table 5 | ANOVA analysis of CCD experiment of the amount of total lipopeptides

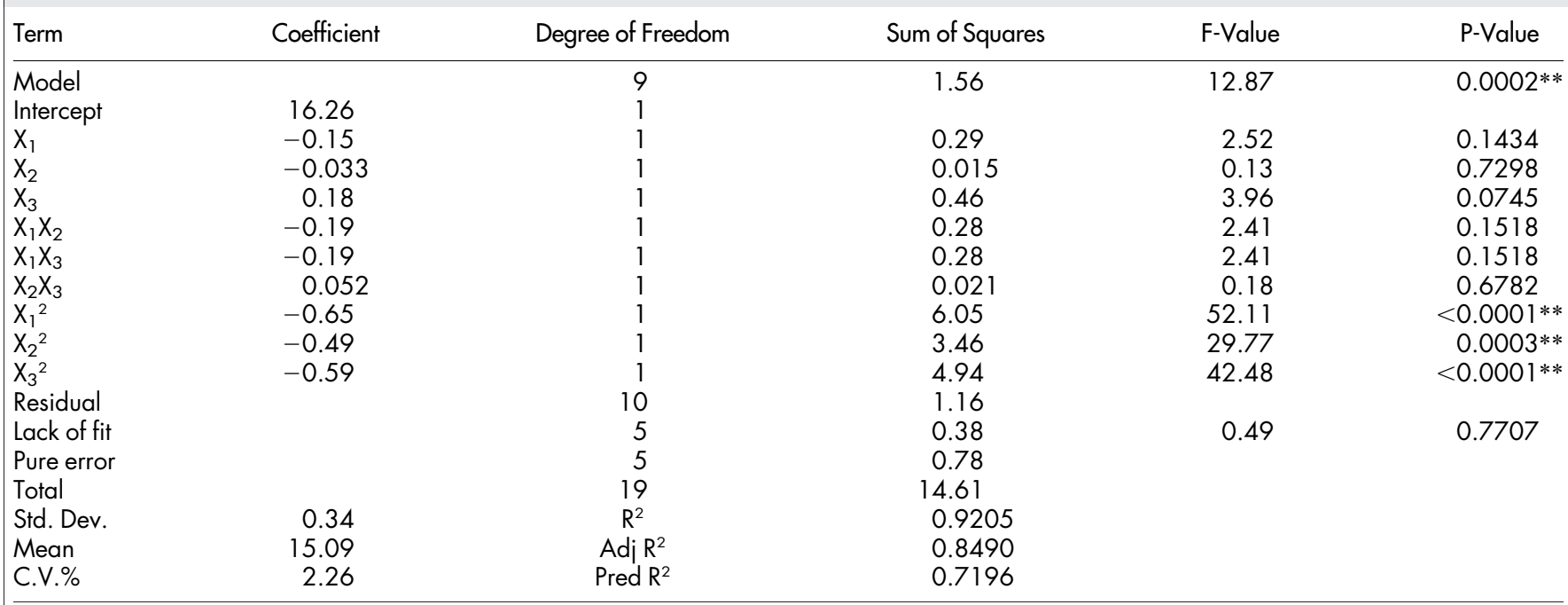

$\mathrm{X}_{1}$ : rapeseed (Brassica napus $\mathrm{L}$.) meal; $\mathrm{X}_{2}$ : expanded feather meal; $\mathrm{X}_{3}$ : dewatered blue algal sludge.

**indicate a significant difference at the 0.01 probability level according to Duncan test.

By solving the quadratic equation model, a maximum cell density of $5.09 \times 10^{8} \mathrm{CFU} / \mathrm{g} \mathrm{DW}$ and a maximum lipopeptides content of $16.26 \mathrm{mg} / \mathrm{g} \mathrm{DW}$ after seven days of SSF with an ambient temperature, inoculation level, initial moisture content and heap turning frequency of $25-30^{\circ} \mathrm{C}, 7.5 \%, 48 \%-50 \%$, and twice per day, respectively, were successfully obtained at an optimum ratio of SSF formula with $7.61 \%$ rapeseed meal, $8.85 \%$ expanded feather meal and $6.47 \%$ dewatered blue algal sludge. This formula was based on both maximum cell density and lipopeptides amount, while the other solutions only considered cell density or lipopeptides content.

Expanded SSF and its physicochemical properties. Two sets, named CK (pure chicken manure inoculated with strain SQR-9) and BIO (optimum material composition inoculated with strain SQR-9), which were organized for the expanded SSF procedure. Table 6 shows the SQR-9 cell density and the amount of lipopeptides in both piles on the final day of SSF. The SQR-9 cell density reached $6.31 \pm 0.26 \times 10^{8} \mathrm{CFU} / \mathrm{g} \mathrm{DW}$ at the final day of SSF and CCD prediction of this value was $5.09 \times 10^{8} \mathrm{CFU} / \mathrm{g} \mathrm{DW}$, while the lipopeptides in the final BIO reached $17.81 \pm 0.72 \mathrm{mg} / \mathrm{g} \mathrm{DW}$ and the prediction value was $16.26 \mathrm{mg} / \mathrm{g}$ DW. This result showed a good correlation between the predicted and measured values, revealing that the RSM method could be used for optimum target results ${ }^{13}$. These two values were only $0.26 \pm 0.03 \times 10^{8} \mathrm{CFU} / \mathrm{g}$ and $5.30 \pm$ $0.88 \mathrm{mg} / \mathrm{g} \mathrm{DW}$ in the control. The results of the verification under optimum conditions in this study were in close agreement to the predicted results, which justified the response model and optimum point ${ }^{24,28}$.

The variations in different physicochemical properties and the results of the toxicity tests are shown in Fig. 3. The temperature of the $\mathrm{CK}$ and $\mathrm{BIO}$ ranged from $25.0^{\circ} \mathrm{C}$ to $27.2^{\circ} \mathrm{C}$ and $26.2^{\circ} \mathrm{C}$ to $51.0^{\circ} \mathrm{C}$ during the 7 days of SSF, respectively (Fig. $3 \mathrm{~A}$ ). The $\mathrm{pH}$ of $\mathrm{BIO}$ increased in the first 4 days and then tended to be stable, with a slight decreasing trend, while the $\mathrm{pH}$ of $\mathrm{CK}$ was relatively stable (Fig. 3B). The variation tendency of EC, an index reflecting the level of salinity in the raw material, of both $\mathrm{CK}$ and $\mathrm{BIO}$ was similar to the $\mathrm{pH}$ results (Fig. $3 \mathrm{C}$ ). Owing to the mineralization of organic matter, the $\mathrm{C} / \mathrm{N}$ ratio for $\mathrm{BIO}$ showed a decreasing trend, while the $\mathrm{CK}$ value was relatively stable (Fig. 3D). Added supplemental materials may promote the growth of strain SQR-9. The variability trends of the NPOC amount in BIO tended to be stable after four days (Fig. 3E), while those of CK showed a slight decreasing trend. The amount of total dissolved nitrogen ( $\mathrm{TNb}$ ) (Fig. 3F) in BIO showed an increasing trend in the first four days and was relatively

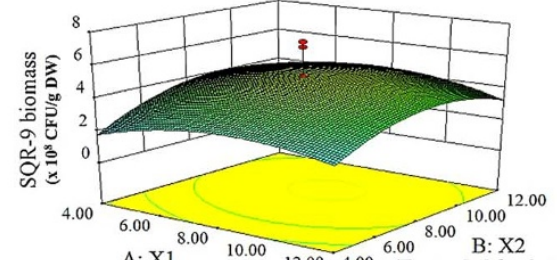

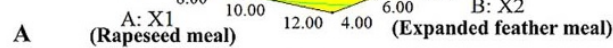

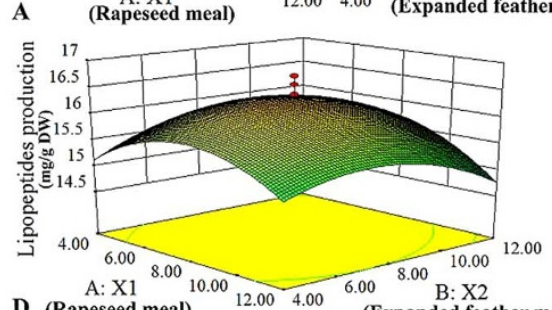

D (Rapeseed meal) $\quad 12.00 \quad 4.00 \quad$ (Expanded feather meal)

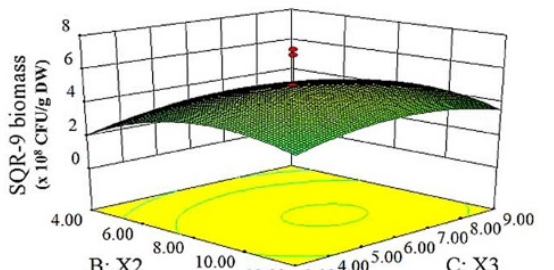

(Blue algal sludge)

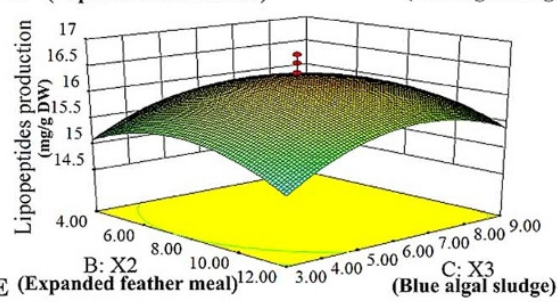

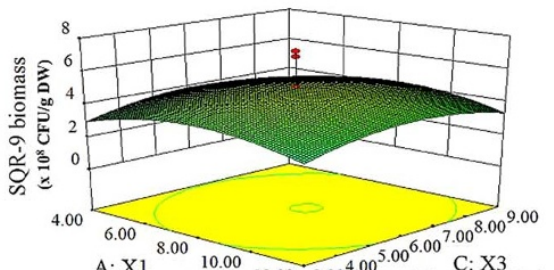
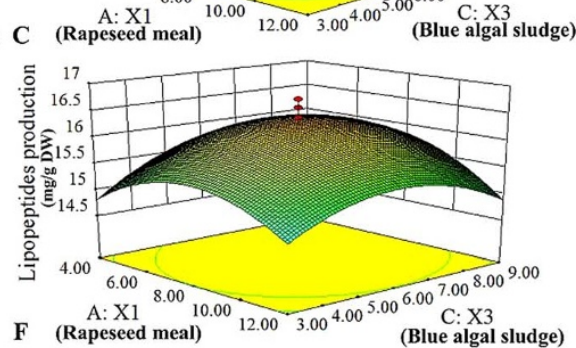

Figure 2 Three-dimensional response surface plot for SQR-9 biomass and the amount of lipopeptides production by utilizing rapeseed meal, expanded feather meal and dewatered blue algal sludge. 
Table 6 | Cell density of SQR-9 and lipopeptides production at the end of SSF

\begin{tabular}{lcc} 
Treatment & $\begin{array}{c}\text { SQR-9 biomass } \\
\left(\times 10^{8} / \mathrm{g} \mathrm{DW}\right)\end{array}$ & $\begin{array}{c}\text { Lipopeptides production } \\
(\mathrm{mg} / \mathrm{g} \mathrm{DW})\end{array}$ \\
\hline $\mathrm{CK}$ & $0.26 \pm 0.03$ & $5.30 \pm 0.88$ \\
$\mathrm{BIO}$ & $6.31 \pm 0.26$ & $17.81 \pm 0.72$ \\
\hline
\end{tabular}

stable after that, while the values for the CK showed a slightly decreasing trend.

MC-LR and MC-RR were degraded from initial concentrations of 0.247 and $6.14 \mu \mathrm{g} \mathrm{g}^{-1} \mathrm{DW}$, respectively, down to undetectable levels $\left(0.1 \mu \mathrm{g} \mathrm{g}^{-1} \mathrm{DW}\right.$ ) at the end of the process (Fig. 3G and Fig. $3 \mathrm{H}$ ). After the end of the SSF, the GI value of the fertilizer produced by the BIO treatment was higher than the CK; however, both fertilizers reached GI values above $60 \%$, indicating that the application of these fertilizers would not injure the plants ${ }^{29}$.

Fluorescence determination of composts. Fig. 4 shows the contours of water extracted organic matter from BIO and CK samples that obtained from SSF process. There are 4 peaks in the contours of BIO
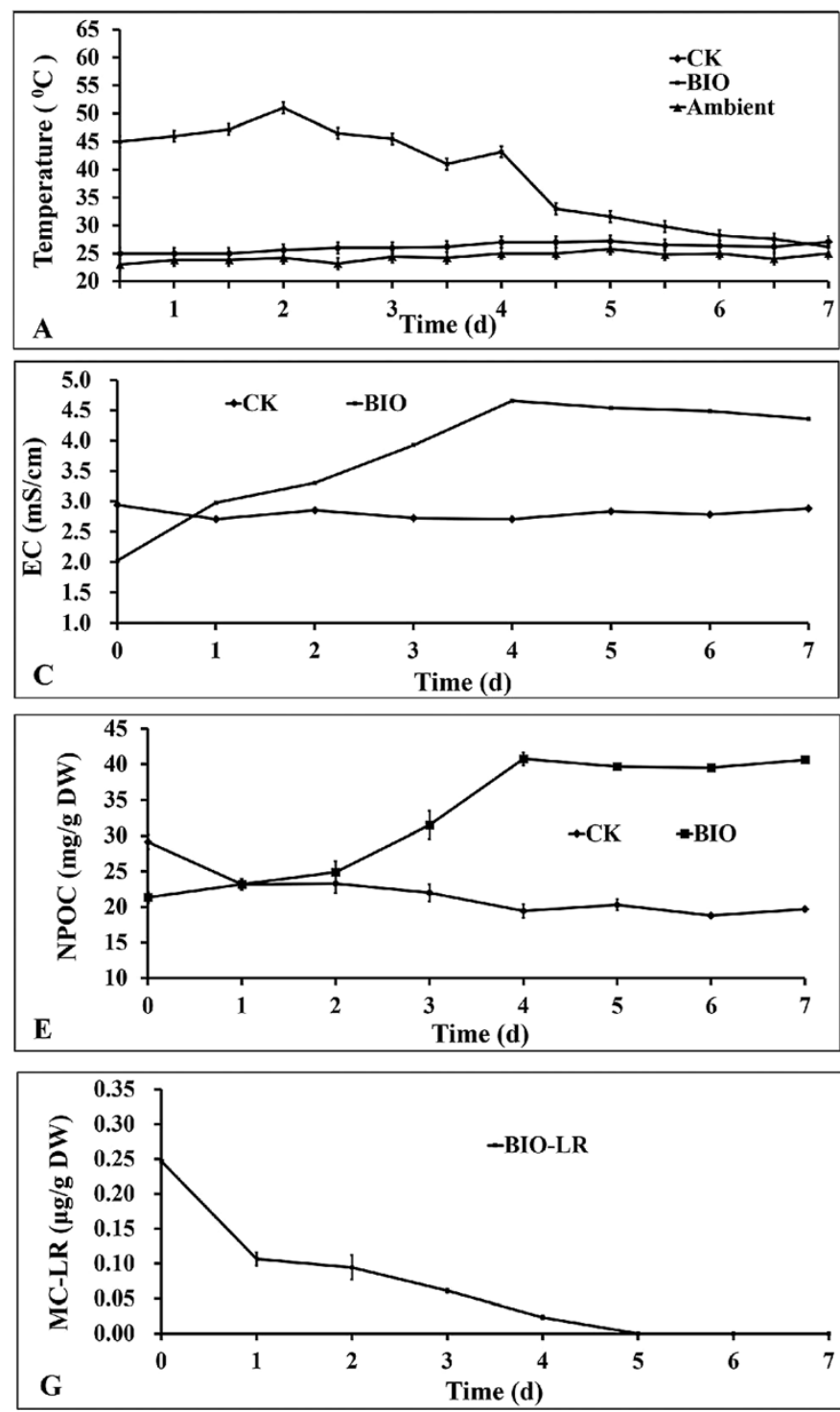

marked as A, B, C and D that are shown in fig.4I-fig.4P. The location of these four peaks are at the wavelengths (Ex/Em) of 330-340/402$428.03,280 / 326-370,220-230 / 318-410$ and 220-250/386-430, respectively, while there are only three obvious peaks in the contours of CK (Peak A, Peak C and Peak D) were detected, which are shown in Fig. 4A-Fig. 4H. According to Chen et al. $(2003)^{6}$, peak A $(\mathrm{Ex}>280 \mathrm{~nm}, \mathrm{Em}>400 \mathrm{~nm})$ represents humic acid-like compounds, and peak B (Ex $>250 \mathrm{~nm}, \mathrm{Em}<350 \mathrm{~nm})$ is attributed to soluble microbial product-like compounds, while Em $>$ $350 \mathrm{~nm}$ is attributed to biological protein-like materials. Peak C $(\mathrm{Ex}<250 \mathrm{~nm}, \mathrm{Em}<350 \mathrm{~nm})$ is ascribed to aromatic proteins, and peak $\mathrm{D}(\mathrm{Ex}<250 \mathrm{~nm}, \mathrm{Em}>350 \mathrm{~nm})$ represents fulvic acidlike materials. Table S3 provides information about the fluorescence EEM results, including peak locations and intensities (revised by QSU). In Fig. 4I-Fig. 4P, peak B rises from a value of 2141 to 8904 on day 4 and then decreases to 7,133 , for reasons linked to the amount of soluble microbial product-like compounds. This result is in agreement with the results of the amount of PGPR during SSF (Fig. S1A), while the intensity of Peak B in CK (Fig. 4A-Fig. 4H) was too low and does not appear in Fig. 4. The intensity of Peak C in CK peaked to 5239 on day 2 , while in BIO, the value increased from 4486 to 18197 and then decreased to 17,073 .
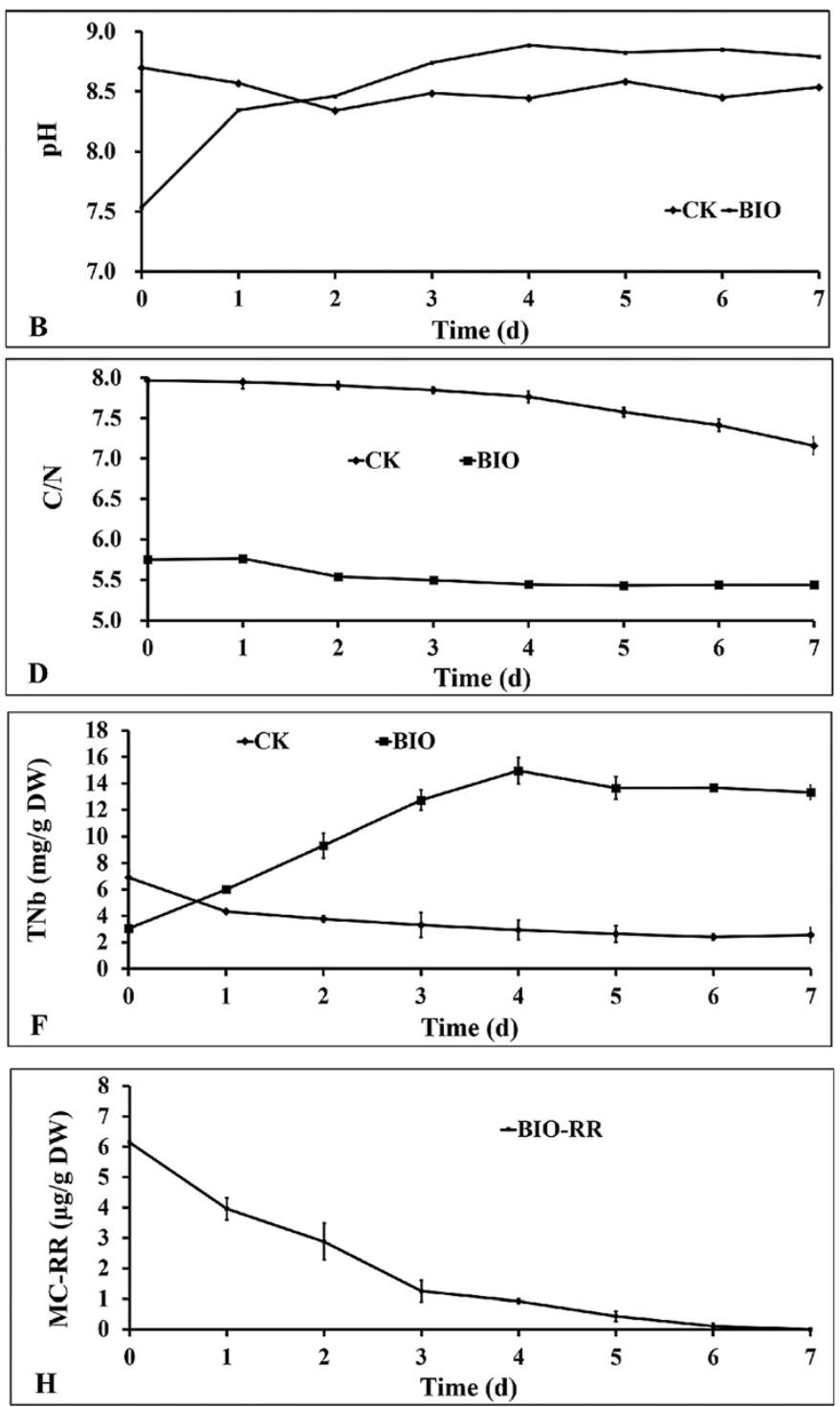

Figure $3 \mid$ Dynamic changes in temperature (A), pH (B), EC (C), C/N (D), NPOC (E), TNb (F), MC-LR (G) and MC-RR (H) during the enlarging composting procedure of CK (Chicken manure with SQR-9) control and BIO (optimum ratio of additives with SQR-9) treatment. 

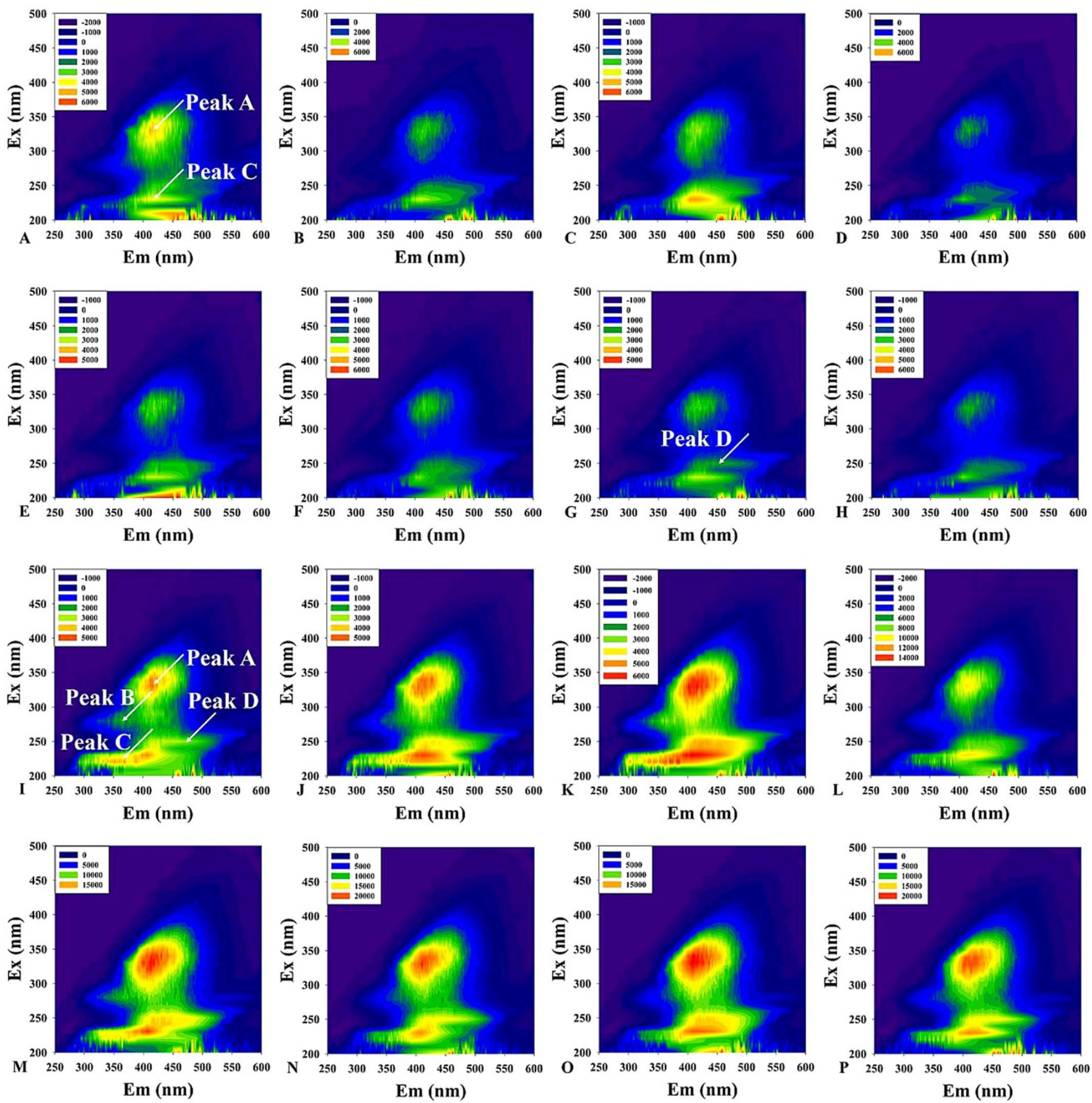

Figure $4 \mid$ Profile of EEM contours during the composting process of CK and BIO. (A) CK $0 \mathrm{~d}$; (B) CK $1 \mathrm{~d}$; (C) CK $2 \mathrm{~d}$; (D) CK $3 \mathrm{~d}$; (E) CK $4 \mathrm{~d}$; (F) CK 5 d; (G) CK 6 d; (H) CK 7 d; (I) BIO 0 d; (J) BIO 1 d; (K) BIO 2 d; (L) BIO 3 d; (M) BIO 4 d; (N) BIO 5 d; (O) BIO 6d and (P) BIO 7 d.

FTIR spectroscopy and Two-dimensional FTIR correlation spectroscopy. Two focused regions of $3100-3700 \mathrm{~cm}^{-1}$ and $900-$ $1800 \mathrm{~cm}^{-1}$ were analyzed in this study due to the characteristic bands in these regions; $900-1,800 \mathrm{~cm}^{-1}$ represents the functional bands in proteins, amide acids, carboxylic acids and carbohydrate groups, while $3100-3700 \mathrm{~cm}^{-1}$ provides information on $\mathrm{OH}$ bands in cellulose $e^{22}$. PCA method was used to normalize one-dimensional FTIR spectra of the initial and final samples for reducing the results noise (Fig. S2). There are 20 and 19 peaks in the initial and final BIO samples, respectively, while the values were 12 and 11 for the CK (Table S4), indicating that more variations of functional groups during SSF were observed in the BIO treatment ${ }^{22}$.

Due to the overlaps of some peaks in the one-dimensional FTIR spectra, two-dimensional (2D) correlation analyses were applied to analyze the order of the different band variations from samples. 2D-FTIR-correlation spectrograms, including synchronous maps and asynchronous maps that are symmetrical to diagonal lines, were observed (Fig. 5), and auto- and cross-peaks, at the diagonal and off-diagonal position in the spectrogram, respectively, were shown.

An auto-peak represents the overall sensibility of the corresponding spectral region as an external perturbation applied to the system to obtain changes in spectral intensity. The higher intensity changes in the band, the deeper color in maps. Along with the external variables, cross-peaks are obtained that provided information on the sequential order of events, which include both positive and negative $e^{22}$ variations and reflected the intensity changes through the colors in maps. 
The peaks above the diagonal were further investigated, and the strongest auto peak intensity was observed at $1020 \mathrm{~cm}^{-1}$ from $\beta$ $(1 \rightarrow 4)$-glucans in polysaccharides followed by $1080 \mathrm{~cm}^{-1}$ from C$\mathrm{O}$ stretching of the polysaccharide group in both of the synchronous maps of $\mathrm{BIO}$ (fig. $5 \mathrm{~A}_{2}$ ) and the synchronous maps of $\mathrm{CK}$ (fig. $5 \mathrm{~A}_{1}$ ) from the range of $900 \mathrm{~cm}^{-1}-1800 \mathrm{~cm}^{-1}$, indicating that polysaccharides were first degraded. In both BIO synchronous maps and CK synchronous maps, there is only one cross peak (1080 and $1020 \mathrm{~cm}^{-1}$ ), which is positively correlated, indicating that those functional groups were synergistic in polysaccharide degradation during the BIO and CK SSF.

In the asynchronous map ranging from $900 \mathrm{~cm}^{-1}-1800 \mathrm{~cm}^{-1}$ of $\mathrm{BIO}$ (fig. 5A 4 ), one negative cross peak $\left(1020\right.$ and $\left.893 \mathrm{~cm}^{-1}\right)$ and six positive cross peaks $\left(1520\right.$ and $1020 \mathrm{~cm}^{-1}, 1460$ and $1020 \mathrm{~cm}^{-1}$, 1650 and $1020 \mathrm{~cm}^{-1}, 1520$ and $1080 \mathrm{~cm}^{-1}, 1460$ and $1080 \mathrm{~cm}^{-1}$ and 1650 and $1080 \mathrm{~cm}^{-1}$ ) were observed. According to Noda's rule ${ }^{16}$ and the BIO asynchronous map, we deduced that the sequence of variation in the peaks' intensity during the BIO SSF is as follows: $893 \mathrm{~cm}^{-1}$ (cellulosic $\beta$-glycosidic linkages), $1520 \mathrm{~cm}^{-1}$ (N-H bending and $\mathrm{C}-\mathrm{N}$ stretching vibrations, cellulose/lignin), $1460 \mathrm{~cm}^{-1}(\mathrm{C}-$ $\mathrm{H}$ band, polysaccharides) and $1650 \mathrm{~cm}^{-1}$ (amide I, protein) $>$ $1020 \mathrm{~cm}^{-1}$ (aliphatic amines, protein) and $1520 \mathrm{~cm}^{-1}(\mathrm{~N}-\mathrm{H}$ bending and $\mathrm{C}-\mathrm{N}$ stretching vibrations, cellulose/lignin), $1460 \mathrm{~cm}^{-1}(\mathrm{C}-\mathrm{H}$ band, polysaccharides) and $1650 \mathrm{~cm}^{-1}$ (amide I, protein) > $1080 \mathrm{~cm}^{-1}$ ( $\mathrm{Si}-\mathrm{O}$ vibrational band, cellulose) (>means faster). Five negative cross peaks in the $\mathrm{CK}$ asynchronous map (Fig. $5 \mathrm{~A}_{3}$ ) were also observed, which were ordered as follows by peak intensity: (1520 and $\left.1020 \mathrm{~cm}^{-1}\right),\left(1520\right.$ and $\left.1080 \mathrm{~cm}^{-1}\right),\left(1690\right.$ and $\left.1020 \mathrm{~cm}^{-1}\right)$, (1460 and $1020 \mathrm{~cm}^{-1}$ ) and (1650 and $\left.1020 \mathrm{~cm}^{-1}\right)$. This order indicated that the substance degradation sequence in $\mathrm{CK}$ is polysaccharides $>$ amide II, cellulose and amide I.

The wave numbers from $3100 \mathrm{~cm}^{-1}$ to $3700 \mathrm{~cm}^{-1}$ provide the details of cellulose degradation during SSF due to the $\mathrm{OH}$ bonds via FTIR $^{10}$. The absorption at the wave number of approximately $3400 \mathrm{~cm}^{-1}$ was usually a demarcation, as values lower than
$3400 \mathrm{~cm}^{-1}$ are intermolecular hydrogen bonds, while those higher than $3400 \mathrm{~cm}^{-1}$ are intra-molecular hydrogen bonds. There is only one auto peak at $3340 \mathrm{~cm}^{-1}$ in the BIO synchronous map (Fig. $5 \mathrm{~B}_{2}$ ) from the range of $3100 \mathrm{~cm}^{-1}-3700 \mathrm{~cm}^{-1}$. This peak was attributed to $\mathrm{O}(3) \mathrm{H} \cdots \mathrm{O}(5)$ intra-molecular $\mathrm{H}$-bonds of cellulose in crystalline cellulose $\mathrm{I} \alpha$ and $\mathrm{I} \beta^{9}$, while one similar auto peak at $3360 \mathrm{~cm}^{-1}$ was observed in the $\mathrm{CK}$ synchronous map (Fig. $5 \mathrm{~B}_{1}$ ). From the vibration of $\mathrm{OH}$ bonds, we can infer that the $\mathrm{OH}$ bond in cellulose was degraded during SSF.

There are four positive cross peaks at 3440 and $3310 \mathrm{~cm}^{-1}, 3520$ and $3310 \mathrm{~cm}^{-1}, 3560$ and $3310 \mathrm{~cm}^{-1}$ and 3610 and $3310 \mathrm{~cm}^{-1}$, and two negative cross peak at 3310 and $3120 \mathrm{~cm}^{-1}$ and 3320 and $3200 \mathrm{~cm}^{-1}$ in the BIO asynchronous map (fig. $5_{4} \mathrm{~B}$ ). There are three positive cross peaks at 3710 and $3340 \mathrm{~cm}^{-1}, 3710$ and $3560 \mathrm{~cm}^{-1}$ and 3710 and $3610 \mathrm{~cm}^{-1}$, and two negative cross peaks at 3570 and $3340 \mathrm{~cm}^{-1}$ and 3610 and $3340 \mathrm{~cm}^{-1}$ in the CK asynchronous map (Fig. $5 \mathrm{~B}_{3}$ ); thus, we inferred that the degradation sequence of $\mathrm{OH}$ bonds according to the Noda's rule ${ }^{16}$ in $\mathrm{BIO}$ is $\mathrm{O}(2) \cdots \mathrm{O}(6)$ intramolecular $\mathrm{H}$-bonds $>\mathrm{O}(6) \cdots \mathrm{O}(3)$ intermolecular $\mathrm{H}$-bonds, while in $\mathrm{CK}$, it is $\mathrm{O}(3) \cdots \mathrm{O}(5)$ intra-molecular $\mathrm{H}$-bonds $>\mathrm{O}(6) \cdots \mathrm{O}(3)$ intermolecular $\mathrm{H}$-bonds $>$ free $\mathrm{OH}(2)$.

\section{Discussion}

From the results of CCD experiment, expanded feather meal was considered to be the most important factor affecting cell density (Table 4). This may be due to the high content of nitrogen, such as amino acids and peptides in expanded feather meal. Proper availability of nutrients in materials could have a significant effect on target production ${ }^{21}$. Moreover, several studies have already shown that some wastes, such as corn flour ${ }^{28}$, blue algal sludge ${ }^{27}$, gourmet meal and soybean cake ${ }^{24}$, could be added as carbon nutrition and nitrogen sources to promote the growth of functional microorganisms and converted to bio-organic fertilizer (BIOs). However, the cost of soybean cake is very high; thus, in our study, rapeseed cake,
CK

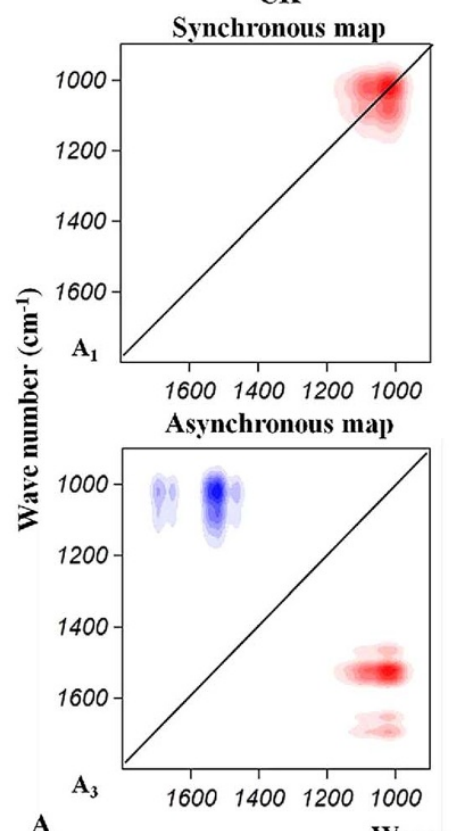

BIO
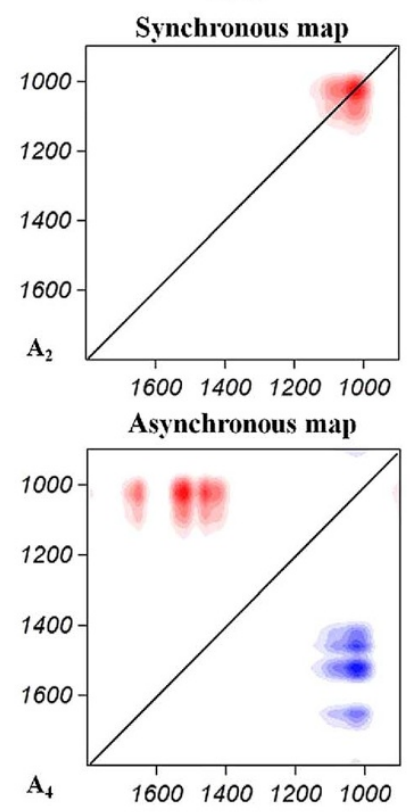
Wave number $\left(\mathrm{cm}^{-1}\right)$

CK

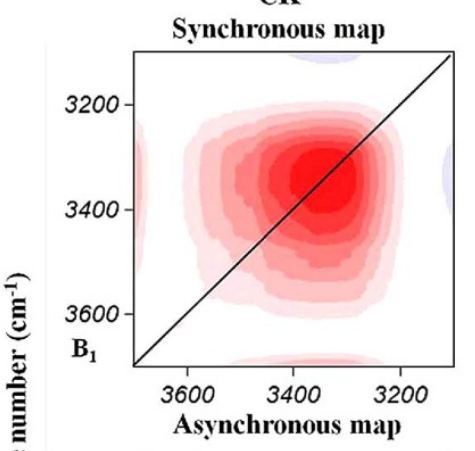

Asynchronous map

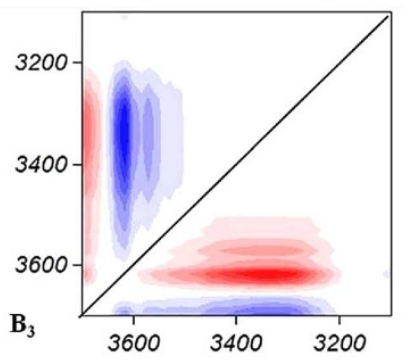

BIO

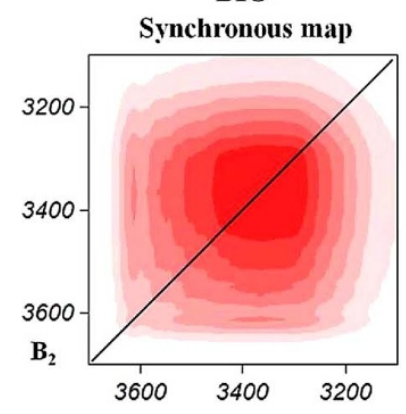

Asynchronous map

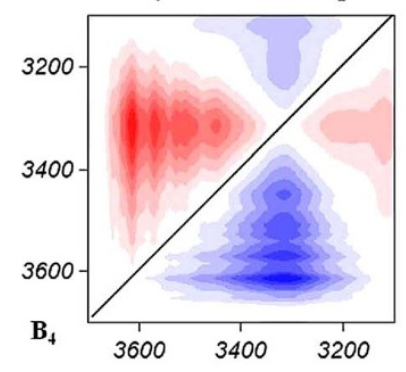

B

Figure $5 \mid$ Profile of 2D FTIR correlation maps obtained from the $900-1,800 \mathrm{~cm}^{-1}$ and 3,100-3,700 $\mathrm{cm}^{-1}$ regions $(\mathrm{n}=8)$ of CK and BIO along with composting time. $\left(A_{1}\right)$ Synchronous map in $900-1,800 \mathrm{~cm}^{-1}$ region of CK; $\left(A_{2}\right)$ synchronous map in $900-1,800 \mathrm{~cm}^{-1}$ region of $B I O ;\left(A_{3}\right)$ asynchronous map in $900-1,800 \mathrm{~cm}^{-1}$ region of CK; $\left(\mathrm{A}_{4}\right)$ asynchronous map in $900-1,800 \mathrm{~cm}^{-1}$ region of $\mathrm{BIO}$; $\left(\mathrm{B}_{1}\right)$ synchronous map in $3,100-3,700 \mathrm{~cm}^{-1}$ region of CK; $\left(B_{2}\right)$ synchronous map in 3,100-3,700 $\mathrm{cm}^{-1}$ region of BIO; $\left(\mathrm{B}_{3}\right)$ asynchronous map in $3,100-3,700 \mathrm{~cm}^{-1}$ region of $\mathrm{CK}$; $\left(\mathrm{B}_{4}\right)$ asynchronous map in $3,100-3,700 \mathrm{~cm}^{-1}$ region of BIO. 
feather powder and dewatered blue algal sludge were selected for further study. Temperature is an important factor in composting process $^{12}$, the results of the experiment of selecting composting parameters indicated that a broad range of ambient temperatures is suitable for SSF in this study.

The SQR-9 cell density and lipopeptides amount in expanded composting process were relevant with CCD experiment, indicating that the CCD experiment can be used in optimize the target. Yong et al. $(2011)^{24}$. and Zhu et al. $(2012)^{28}$. reported the similar results that CCD experiment was relevant with expanded $\mathrm{SSF}^{24,28}$. Composting is a safe way to utilize organic wastes and reduce harmful matter. In this study, microcystins, a group of monocyclic heptapeptides that is harmful to healthy of people and could not be easily degraded by conventional methods due to their thermo-stability and lack of volatility after boiling ${ }^{11}$ were rapidly degraded. In accordance with our results, some similar results were already reported that microcystuns can be rapidly biodegraded during composting or SSF ${ }^{11,27}$. In addition, a positive correlation between the PGPR cell density and the amount of lipopeptides was observed in our study. The results were in accordance with previous works ${ }^{4,7,24,28}$ that the promotion of cell density growth and lipopeptides production as secondary metabolites during the growth of PGPRs after the addition of supplemental $^{15,20}$ nutrient materials, such as carbon and nitrogen, were reported. That is to say, SSF provides an opportunity to reduce the costs of raw materials in the production of optimized target.

After validation experiment of optimized experiment, $7.61 \%$ rapeseed meal, $8.85 \%$ expanded feather meal, $6.47 \%$ dewatered blue algal sludge and $77.07 \%$ chicken manure were established as SSF substrates to get maximum SQR-9 biomass as $6.31 \pm 0.26 \times$ $10^{8} \mathrm{CFU} / \mathrm{g}$ DW and maximum amount of lipopeptides as $17.81 \pm$ $0.72 \mathrm{mg} / \mathrm{g}$ DW. Similar to our results, the former studies have also demonstrated that oil rapeseed cakes, usually $40 \%$ dry weight (DW), could lead to much better growth of microbial species added during the BIO preparation by providing more nutrients than $100 \%$ matured composts ${ }^{3}$. However, the price of rapeseed cake was so high that lead to increase the price of $\mathrm{BIO}^{27}$, which limiting the large use of BIOs for China. Zhang et al. $(2014)^{27}$, has used blue algal sludge to replace the oil rapeseed cakes in BIO to reduce the price of BIO. However, the results showed that the cell density of strain SQR-9 only reached $5 \times 10^{7} \mathrm{CFU} / \mathrm{g} \mathrm{DW}$. And in our study, the cell density of strain SQR-9 could reach more than $10^{8} \mathrm{CFU} / \mathrm{g} \mathrm{DW}$ and the cost for the produced BIO was only US\$114.90, which is significantly lower than that in the previous method. Thus, this kind of BIO produced via the novel SSF process can may be more competitive in the market not only in price but also in good quality.

This study marks the first investigation of monitoring SSF process by fluorescence determination, and results showed that adding raw materials in BIO increased the peak intensity (Table S3) which linked to the dissolved organic matter ${ }^{26}$. The results confirmed that the easy-degraded materials in BIO was utilized by microbes and then the heat was released, subsequently enhancing the SSF process ${ }^{11}$. In addition, along with the SSF process, the aromatic materials which are part of humic-materials and fulvic-materials that linked to the maturity of fertilizer ${ }^{6}$ were formed and the SQR-9 cell density increased, indicating that high temperature and nutrients promoted the PGPR growth.

From the BIO asynchronous map (900-1800 $\mathrm{cm}^{-1}$ ), the sequence of variation of the peaks' intensity suggests that the protein was degraded before polysaccharide and cellulose degradation as a consequence of the characteristics of added raw materials in $\mathrm{BIO}^{16}$. Expanded feather powder, rapeseed meal and dewatered blue algal sludge contain high amounts of protein and amino acids $s^{3,4,11,27}$ that provided the nutrients for the growth of PGPR, which in this study utilized protein is much more easily than polysaccharides and cellulose. While in CK, the results of the sequence suggest polysaccharides were first degraded during the CK composting followed by amide materials and then cellulose. This result agrees with the results of the SSF temperature changes (Fig. 3A) and the cell density of PGPR in CK, which was lower than in BIO.

In conclusion, a novel bio-organic fertilizer by response surface methodology with an optimized composition of SSF raw materials was obtained in this study. The results of the verification experiment on the optimized composition revealed a good correlation between predicted and measured values, of which the maximum cell biomass was $6.31 \pm 0.26 \times 10^{8} \mathrm{CFU} / \mathrm{g} \mathrm{DW}$ and the maximum amount of lipopeptides was $17.81 \pm 0.72 \mathrm{mg} / \mathrm{g} \mathrm{DW}$ after 7 days SSF under optimized conditions. This kind of BIO have more competitive in market not only in price but also in high quality. The spectroscopy experiments showed direct evidence of raw materials transformation during the novel SSF, in which the BIO had higher dissolved organic matter and the protein was degraded first in the novel SSF.

\section{Methods}

Organism, compost, wastes protein sources and selection of SSF parameters. The bacterial strain Bacillus amyloliquefaciens SQR9 and all of the composts and supplemental nutrient materials were provided by the Jiangsu Key Lab for Solid Organic Waste Utilization, Jiangsu, China, except for the dewatered blue algal sludge. SQR-9 cells maintained on a $2.5 \%$ LB agar plate were pre-cultured in LB medium at $170 \mathrm{rpm}$ and $30^{\circ} \mathrm{C}$ for $36 \mathrm{~h}$, harvested by centrifugation at $6000 \mathrm{rpm}$ for $5 \mathrm{~min}$, washed three times with sterilized water, and suspended in the same volume of water prior to inoculation. The Algal sludge was obtained on-site at Taihu Lake and collected in a storage pool for a few months prior to use. The properties of all raw materials used in SSF in this study are listed in Table S1.

The solid-state fermentation (SSF) media containing chicken manure compost (80\% DW), oil rapeseed (Brassica napus L.) meal (10\% DW) and feather powder $(10 \% \mathrm{DW})$ were arranged in small, cone-shaped windrows $(0.15 \mathrm{~m}$ high by $0.3 \mathrm{~m}$ diameter base, approximately $3 \mathrm{~kg} \mathrm{DW}$ each) and solid-state fermented for $7 \mathrm{~d}$ at ambient temperature for parameters selection. The effects of the following conditions on the SSF process were examined: composting days $(1 \mathrm{~d}, 3 \mathrm{~d}, 5 \mathrm{~d}$ and $7 \mathrm{~d})$, fermentation temperature $\left(20^{\circ} \mathrm{C}, 25^{\circ} \mathrm{C}, 30^{\circ} \mathrm{C}, 35^{\circ} \mathrm{C}, 40^{\circ} \mathrm{C}\right.$ and $\left.45^{\circ} \mathrm{C}\right)$, the initial moisture content values of the mixtures (adjusted to $35 \%-65 \%$ at $5 \%$ intervals for the first round and $45 \%, 47 \%, 49 \%$ and $51 \%$ for the second round), the initial inoculation amounts (set at $1 \%, 5 \%, 7.5 \%, 10 \%, 12.5 \%$, and $15 \%$ ), and heap turning frequency (once, twice, three times a day and no turning). After the turning of the piles, five sub-samples were taken from symmetrical locations around the heap and combined to form a composite sample. Triplicate composite samples were collected and stored at $4{ }^{\circ} \mathrm{C}$ immediately prior to analysis. The number of B. amyloliquefaciens SQR-9 were determined according to Zhang et al. $(2014)^{27}$. Each treatment was replicated three times.

Selection of composting ingredient (single factor experiment). Chicken manure compost mixed with nine supplemental nutrient materials, including oil rapeseed meal, expanded feather powder, soybean cake, corn flour, gourmet meal, Chinese herbs residues, castor cake, vinegar residue and dewatered blue algal sludge with different additive concentrations (Table S2), was arranged in small, cone-shaped windrows to test the effects of the various nutrient materials on strain SQR-9 biomass after 7 days SSF, with the optimum moisture content, suitable heap turning frequency and initial inoculation size at the ambient temperature. Each treatment was replicated three times.

Plackket-Burman design experiment (PBD). In view of the results from the single factor experiments, seven variables, including soybean cake, oil rapeseed (Brassica napus L.) meal, corn flour, expanded feather powder, dewatered blue algal sludge, castor cake and monosodium glutamate meal, showing significant effects on strain SQR-9 biomass were chosen for further study and named $\mathrm{BX}_{1}, \mathrm{BX}_{2}, \mathrm{BX}_{3}, \mathrm{BX}_{4}, \mathrm{BX}_{5}$, $\mathrm{BX}_{6}$ and $\mathrm{BX}_{7}$, respectively. Minitab software (Minitab Inc., USA) was used to design the experiment, as shown in Table 1 . Each variable was established at a high level $(+1)$ and a low level $(-1)$. Significant factors were chosen for further optimized experiments according to the Minitab (R) 16.0 analysis results (Minitab Inc., USA).

Path of steepest ascent experiment. The path of steepest ascent experiment ${ }^{24}$ was conducted to obtain optimal response region that the variables were rapeseed meal $\left(\mathrm{BX}_{2}\right)$, expanded feather powder $\left(\mathrm{BX}_{4}\right)$ and dewatered blue algal sludge $\left(\mathrm{BX}_{5}\right)$, which was based on the $\mathrm{PBD}$ experiment results. Optimal region was moving rapidly along the path of steepest ascent until no further response was observed.

Optimization of the ingredient portion for SSF by a central composite design (CCD) experiment. To obtain the maximum biomass of strain SQR-9, response surface methodology was chosen for optimizing the blending ratio of ingredients. Three variables were selected based on the PBD experiment, i.e., rapeseed meal $\left(\mathrm{BX}_{2}\right)$, feather powder $\left(\mathrm{BX}_{4}\right)$ and dewatered blue algal sludge $\left(\mathrm{BX}_{5}\right)$, and renamed as $\mathrm{X}_{1}, \mathrm{X}_{2}$ and $\mathrm{X}_{3}$, respectively. A central composite design (CCD) experiment was performed to 
determine the best ingredient portion for maximizing the SQR-9 biomass. Coded levels and real values are shown in Table 2.

The following quadratic equation was applied to obtain the predicted biomass of strain SQR-9 (Y) and explain the roles of these independent variables $\left(\mathrm{X}_{1}, \mathrm{X}_{2}\right.$ and $\left.\mathrm{X}_{3}\right)$ and their interactions ${ }^{24}$ :

$$
Y=\beta_{0}+\sum_{i=1}^{n} \beta_{i} X_{i}+\sum_{i=1}^{n} \beta_{i i} X_{i}^{2}+\sum_{i=1}^{n-1} \sum_{j=i+1}^{n} \beta_{i j} X_{i} X_{j}
$$

where $\mathrm{Y}$ is the response of strain SQR-9 biomass; $\mathrm{X}_{1}, \mathrm{X}_{2}$ and $\mathrm{X}_{3}$ are the independent variables; $\beta_{0}$ is intercept constant; $\beta_{1}, \beta_{2}, \beta_{3}$ are linear coefficients; $\beta_{11}, \beta_{22}, \beta_{33}$ are quadratic coefficients; and $\beta_{12}, \beta_{13}, \beta_{23}$ are interaction coefficients.

Design-Expert version 8.0.6 (Stat-Ease, Inc., Minneapolis, MN, USA) was used for statistical regression analysis and to confirm the significance of the quadratic equation, coefficient of determination $\left(\mathrm{R}^{2}\right)$ and adjusted $\mathrm{R}^{2}\left(\text { Adj } \mathrm{R}^{2}\right)^{18}$.

The optimum blending ratio of supplemental nutrient materials for maximizing strain SQR-9 biomass was obtained by solving the regression equation, and the final reduced model was obtained using analysis of variance (ANOVA), where the threshold of statistical significance was $\mathrm{P}<0.05$. This model can be estimated using Design-Expert version 8.0 .6 by varying two variance levels while the other is kept at a constant value as a decisive three-dimensional (3D) response surface plot.

Lipopeptides extraction and quantification. Lipopeptides were extracted from SSF samples according to Zhu et al. $(2012)^{28}$. The amount was expressed as milligram per gram of initial dry sample (mg/g DW). The following quadratic expansion equation can predict the response in terms of the lipopeptides amount:

$$
\begin{aligned}
Y= & \beta_{0}+\beta_{1} \mathrm{X}_{1}+\beta_{2} \mathrm{X}_{2}+\beta_{3} \mathrm{X}_{3}+\beta_{11} \mathrm{X}_{1}^{2}+\beta_{22} \mathrm{X}_{2}^{2} \\
& +\beta_{33} \mathrm{X}_{3}^{2}+\beta_{12} \mathrm{X}_{1} \mathrm{X}_{2}+\beta_{13} \mathrm{X}_{1} \mathrm{X}_{3}+\beta_{23} \mathrm{X}_{2} \mathrm{X}_{3}
\end{aligned}
$$

where $\mathrm{Y}$ is the response of the amount of lipopeptides; $\mathrm{X}_{1}, \mathrm{X}_{2}$ and $\mathrm{X}_{3}$ are the independent variables; $\beta_{0}$ is the intercept constant; $\beta_{1}, \beta_{2}, \beta_{3}$ are linear coefficients; $\beta_{11}, \beta_{22}, \beta_{33}$ are quadratic coefficients; and $\beta_{12}, \beta_{13}, \beta_{23}$ are interaction coefficients.

Experimental validation of the optimum ingredient portion using an expanded SSF process. An optimum blending ratio of 7.61: 8.85: 6.47: 77.07 (rapeseed meal: expanded feather meal: dewatered blue algal sludge: chicken manure, DW) (BIO) and chicken manure (CK) with $7.5 \%$ inoculation levels (v/wt) of strain SQR-9 were arranged in small, cone-shaped windrows $(0.7 \mathrm{~m}$ high by $0.75 \mathrm{~m}$ diameter at base, approximately $20 \mathrm{~kg}$ DW each) for the expanded SSF for 7 days. The other operations were performed as previously described. The temperature of the piles, $\mathrm{pH}$, electrical conductivity (EC), non-purge-able organic carbon (NPOC), total dissolved nitrogen (TNb), total carbon, nitrogen content, microcystin-LR, microcystin-RR concentrations and germination index were all determined according to Huang et al. $(2014)^{11}$. The methods for counting functional bacterial numbers and the quantification of the lipopeptides amount were described above.

Fluorescence determination and EEM analysis. The fluorescence determination method was performed according to $\mathrm{Yu}$ et al. (2010) ${ }^{26}$ with some modifications. Briefly, the $\mathrm{pH}$ of the fresh fertilizer sample extracts was first adjusted to 7.0 before the samples were filtered through $0.45 \mu \mathrm{m}$ polytetrafluoroethylene (PTFE) filters; then, the filtrate was diluted to make the total dissolved organic carbon less than $10 \mathrm{mg} \mathrm{kg}^{-1}$ using double distilled water. Fluorescence EEMs were measured using a Varian Eclipse fluorescence spectrophotometer. For EEM, emission (Em) spectra from 250 to $600 \mathrm{~nm}$ were obtained with $2 \mathrm{~nm}$ increments by varying the wavelength of excitation (Ex) from 200 to $500 \mathrm{~nm}$ with $10 \mathrm{~nm}$ increments. The scanning velocity was $1200 \mathrm{~nm} \mathrm{~min}{ }^{-1}$ when the slit width of emission and excitation attained $5 \mathrm{~nm}$. Quinine sulfate units (QSU) was used to calibrate the fluorescence intensity, and the maximum fluorescence intensity of $0.01 \mathrm{mg} \mathrm{L}^{-1}$ quinine in $1 \mathrm{M} \mathrm{H}_{2} \mathrm{SO}_{4}$ at the $\mathrm{Ex} / \mathrm{Em}$ of $350 / 450 \mathrm{~nm}$ was defined as $1 \mathrm{QSU}^{23}$. To reduce the NPOC effect on fluorescence EEM, the results were further normalized as QSU per NPOC at the same dilution.

Fourier-transform infrared (FTIR) spectroscopy and 2D correlation spectroscopy of FTIR. A sample of three replicates was mixed with one subsample that was air dried, ground to pass through a $0.15 \mathrm{~mm}$ sieve and mixed with $\mathrm{KBr}$ (sample: $\mathrm{KBr}$ $=1: 200, \mathrm{DW})$; then, the mixture was compressed to slice under a pressure of $10 \mathrm{t} \mathrm{cm}^{-2}$. Pure $\mathrm{KBr}$ was used as the baseline value. FTIR spectra were obtained in the wavelength range from 400 to $4000 \mathrm{~cm}^{-1}$ with $2 \mathrm{~mm}$ increments using a Nicolet iS10 FTIR spectrometer (Thermo Fisher Scientific Corp., MA, USA) equipped with OMNIC software. The FTIR spectra were normalized by summing the absorbance from $400 \mathrm{~cm}^{-1}$ to $4000 \mathrm{~cm}^{-1}$ and then multiplying by 1000 according to $\mathrm{Yu}$ et al. $(2010)^{26}$. Principal components analysis (PCA) was used to reduce the noise level that followed. Finally, 2Dshige software (Kwansei-Gakuin University, Japan) was used to conduct 2D correlation spectroscopy. SSF time was regarded as an external perturbation according to Wang et al. (2012) $)^{22}$, and the synchronous correlation intensity was calculated using the following equation:

$$
\Phi\left(\mathrm{x}_{1}, \mathrm{x}_{2}\right)=\frac{1}{\mathrm{~m}-1} \sum_{j=1}^{m} \tilde{\boldsymbol{I}}_{j}\left(\boldsymbol{X}_{1}\right) \tilde{\boldsymbol{I}}_{j}\left(\boldsymbol{X}_{2}\right)
$$

Asynchronous correlation can be determined from Eq. 8:

$$
\varphi\left(\mathrm{x}_{1}, \mathrm{x}_{2}\right)=\frac{1}{\mathrm{~m}-1} \sum_{j=1}^{m} \tilde{\boldsymbol{I}}_{j}\left(\boldsymbol{X}_{1}\right) \sum_{k=1}^{m} \boldsymbol{N}_{j k} \tilde{\boldsymbol{I}}_{j}\left(\boldsymbol{X}_{2}\right)
$$

$\mathrm{X}$ is the FTIR spectra, which is in accordance with the perturbation of the variable $\mathrm{t}$. $I(\mathrm{x}, \mathrm{t})$ is the spectrum at $\mathrm{m}$ evenly spaced points in $\mathrm{t}\left(\mathrm{T}_{\min }-\mathrm{T}_{\max }\right)$, which is expressed as:

$$
I_{j}(X)=I\left(x, t_{j}\right), j=1,2, \ldots, m
$$

A set of dynamic spectra is given as follows:

$$
\tilde{\boldsymbol{I}}(\mathrm{x}, \mathrm{t})=\mathrm{I}\left(\mathrm{x}, \mathrm{t}_{\mathrm{j}}\right)-\overline{\boldsymbol{I}}(\mathrm{x})
$$

where $\bar{I}(\mathrm{x})$ expresses the reference spectrum and $\mathrm{N}_{\mathrm{jk}}$ is related to the $\mathrm{j}_{\mathrm{th}}$ column and the $\mathrm{k}_{\mathrm{th}}$ raw element from the Hilbert-Noda transformation matrix, which is defined as:

$$
\mathrm{N}_{\mathrm{jk}}=\left\{\begin{array}{cc}
0 & \text { if }(\mathrm{j}=\mathrm{k}) \\
\frac{1}{\pi(\mathrm{k}-\mathrm{j})} & \text { otherwise }
\end{array}\right.
$$

$\Phi\left(\mathrm{X}_{1}, \mathrm{X}_{2}\right)$ represents simultaneous changes in two spectral intensities at $\mathrm{X}_{1}$ and $\mathrm{X}_{2}$ during $\mathrm{T}_{\min }-\mathrm{T}_{\max }$, while $\varphi\left(\mathrm{X}_{1}, \mathrm{X}_{2}\right)$ contains out-of-phase or sequential changes at $\mathrm{X}_{1}$ and $\mathrm{X}_{2}$ during the same time intervals, according to Wang et al. $(2012)^{22}$.

Statistical analysis. All experiments were conducted in triplicate. SPSS version 17.0 was used for statistical analysis (SPSS Inc., Chicago, IL). Differences among treatments were assessed via one-way ANOVA, and the calculated means were subjected to Duncan's multiple range test at $\mathrm{P}=0.05$. The results are expressed as the mean \pm S.D. The other statistical analysis methods are described above.

1. Ait Baddi, G. et al. Characterization of fulvic acids by elemental and spectroscopic (FTIR and ${ }^{13} \mathrm{C}-\mathrm{NMR}$ ) analyses during composting of olive mill wastes plus straw. Bioresour. Technol. 93, 285-290 (2004).

2. Ann, R. \& Shannon, E. G. How Microbes can Help Feed the World: Report on an American Academy of Microbiology Colloquium (American Society For Microbiology, Washington DC, 2013).

3. Cao, Y. et al. Bacillus subtilis SQR 9 can control Fusarium wilt in cucumber by colonizing plant roots. Biol. Fert. Soils 47, 495-506 (2011).

4. Chen, L. H. et al. Solid-state fermentation of agro-industrial wastes to produce bioorganic fertilizer for the biocontrol of Fusarium wilt of cucumber in continuously cropped soil. Bioresour. Technol. 102, 3900-3910 (2011).

5. Chen, L. H. et al. An antifungal compound from Trichoderma harzianum SQRT037 effectively controls Fusarium wilt of cucumber in continuously cropped soil. Australas. Plant Path. 41, 239-245 (2012).

6. Chen, W., Westerhoff, P., Leenheer, J. A. \& Booksh, K. Fluorescence excitationemission matrix regional integration to quantify spectra for dissolved organic matter. Environ. Sci. Technol. 37, 5701-5710 (2003).

7. Colla, L. M. et al. Simultaneous production of lipases and biosurfactants by submerged and solid-state bioprocesses. Bioresour. Technol. 101, 8308-8314 (2010).

8. Esitken, A. et al. Potential use of plant growth promoting rhizobacteria (PGPR) in organic apricot production. In Proceedings of the International Scientific Conference: Environmentally Friendly Fruit Growing (Polli Estonia, Tartu University Press, 2005) pp. 90-97.

9. Gurav, R. G. \& Jadhav, J. P. A novel source of biofertilizer from feather biomass for banana cultivation. Enviro. Sci. Pollut. Res. 20, 4532-4539 (2013).

10. Hinterstoisser, B. \& Salmén, L. Application of dynamic 2D FTIR to cellulose. Vib. Spectrosc. 22, 111-118 (2000).

11. Huang, Y. et al. Novel resource utilization of refloated algal sludge to improve the quality of organic fertilizer. Environ. Technol. 35, 1658-1667 (2014).

12. Jackson, A. M., Whipps, J. M. \& Lynch, J. M. Effects of temperature, pH and water potential on growth of the four fungi with disease biocontrol potential. World J. Microbiol. Biotechnol. 7, 494-501 (1991).

13. Khuri, A. I. \& Cornell, J. A. Response Surfaces: Design and Analysis (Vol. 152) (CRC press, New York, 1987).

14. Kundsen, G. R. \& Li, B. Effects of temperature, soil moisture, and wheat brab on growth of Trichoderma harzianum from the alginate pellets. Phytopathology $\mathbf{9 0}$, 724-727 (1990).

15. Lerch, R. N., Barbarick, K. A., Sommers, L. E. \& Westfall, D. G. Sewage sludge proteins as labile carbon and nitrogen sources. Soil Sci. Soc. Am. J. 56, 1470-1476 (1992). 
16. Noda, I. Recent advancement in the field of two-dimensional correlation spectroscopy. J. Mol. Struct. 883, 2-26 (2008)

17. O'Connell, P. F. Sustainable agriculture: a valid alternative. Outlook Agric. 21, 5-12 (1992).

18. Raza, W. et al. Evaluation of metal ions $\left(\mathrm{Zn}^{2+}, \mathrm{Fe}^{3+}\right.$ and $\left.\mathrm{Mg}^{2+}\right)$ effect on the production of fusaricidin-type antifungal compounds by Paenibacillus polymyxa SQR-21. Bioresour. Technol. 101, 9264-9271 (2010).

19. Reddy, L. V. A., Wee, Y. J., Yun, J. S. \& Ryu, H. W. Optimization of alkaline protease production by batch culture of Bacillus sp. RKY2 through PlackettBurman and response surface methodological approaches. Bioresour. Technol.99, 2242-2249 (2008).

20. Sánchez-Monedero, M. A., Roig, A., Paredes, C. \& Bernal, M. P. Nitrogen transformation during organic waste composting by the Rutgers system and its effects on $\mathrm{pH}, \mathrm{EC}$ and maturity of the composting mixtures. Bioresour. Technol. 78, 301-308 (2001).

21. Tari, C., Genckal, H. \& Tokath, F. Optimization of a growth medium using a statistical approach for the production of an alkaline protease from a newly isolated Bacillus sp. L21. Process Biochem. 41, 659-666 (2006).

22. Wang, L. P. et al. Fate of biopolymers during rapeseed meal and wheat bran composting as studied by two-dimensional correlation spectroscopy in combination with multiple fluorescence labeling techniques. Bioresour. Technol. 105, 88-94 (2012).

23. Xu, H. C., He, P. J., Wang, G. Z. \& Shao, L. M. Three-dimensional excitation emission matrix fluorescence spectroscopy and gel-permeating chromatography to characterize extracellular polymeric substances in aerobic granulation. Water Sci. Technol. 61, 2931-2942 (2010).

24. Yong, X. Y. et al. Optimization of the production of poly- $\gamma$-glutamic acid by Bacillus amyloliquefaciens $\mathrm{C} 1$ in solid-state fermentation using dairy manure compost and monosodium glutamate production residues as basic substrates. Bioresour. Technol. 102, 7548-7554 (2011).

25. Yong, X. Y. et al. Dynamics of bacterial communities during solid-state fermentation using agro-industrial wastes to produce poly- $\gamma$-glutamic acid, revealed by real-time PCR and denaturing gradient gel electrophoresis (DGGE). Appl. Microbiol. Biot. 92, 717-725 (2011).

26. Yu, G. H. et al. PARAFAC modeling of fluorescence excitation- emission spectra for rapid assessment of compost maturity. Bioresour. Technol. 101, 8244-8251 (2010).

27. Zhang, M. et al. Algal sludge from Taihu Lake can be utilized to create novel PGPR-containing bio-organic fertilizers. J. Environ. Manage. 132, 230-236 (2014)
28. Zhu, Z. et al. Production of lipopeptides by Bacillus amyloliquefaciens XZ-173 in solid state fermentation using soybean flour and rice straw as the substrate. Bioresour. Technol. 112, 254-260 (2012).

29. Zucconi, F., Forte, M., Monaco, A. \& Debertold, M. Biological evaluation of compost maturity. Biocycle 22, 27-29 (1981).

\section{Acknowledgments}

This research was supported by the National Key Basic Research Program of China (2015CB150506), the Chinese Ministry of Science and Technology (2013AA102802), the Priority Academic Program Development of the Jiangsu Higher Education Institutions (PAPD), 111 project (B12009), the Agricultural Ministry of China (201103004), the Key Technology R\&D Program of Jiangsu, China (BE2012377), the Jiangsu Postdoctoral Science Foundation (1102079C), and the China Postdoctoral Science Foundation (2011M501248) and (2012T50479).

\section{Author contributions}

Y.H. mainly performed the experiments. L.S., J.Z. and R.H. helped with the experiments R.L. and Q.S. conceived and designed the experiments. Y.H. wrote the main manuscript text. R.L. and Q.S. helped preparing and revised the manuscript. All authors discussed the results and commented on the manuscript by reviewing it accurately.

\section{Additional information}

Supplementary information accompanies this paper at http://www.nature.com/ scientificreports

Competing financial interests: The authors declare no competing financial interests.

How to cite this article: Huang, Y. et al. Utilization of different waste proteins to create novel PGPR-containing bio-organic fertilizer. Sci. Rep. 5, 7766; DOI:10.1038/srep07766 (2015)

This work is licensed under a Creative Commons Attribution-NonCommercialNoDerivs 4.0 International License. The images or other third party material in this article are included in the article's Creative Commons license, unless indicated otherwise in the credit line; if the material is not included under the Creative Commons license, users will need to obtain permission from the license holder in order to reproduce the material. To view a copy of this license, visit http:// creativecommons.org/licenses/by-nc-nd/4.0/ 